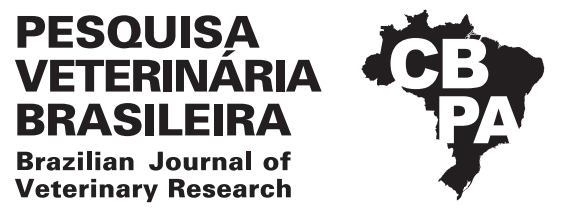

Pesq. Vet. Bras. 38(8):1622-1630, agosto 2018 DOI: 10.1590/1678-5150-PVB-5114

Original Article

ISSN 0100-736X (Print)

ISSN 1678-5150 (Online)

\title{
Left atrial size and contractile function in healthy dogs and dogs with chronic mitral valve disease ${ }^{1}$
}

\author{
Lilian C. Petrus ${ }^{2 *}$, Jacqueline R. Castro ${ }^{3}$, Matheus M. Mantovani ${ }^{3}$, \\ André M. Gimenes ${ }^{3}$, Caio N. Duarte ${ }^{3}$, Guilherme T. Goldfeder ${ }^{3}$, Denise S. Schwartz ${ }^{3}$ \\ and Maria Helena M.A. Larsson ${ }^{3}$
}

\begin{abstract}
Petrus L.C., Castro J.R., Mantovani M.M., Gimenes A.M., Duarte C.N., Goldfeder G.T., Schwartz D.S. \& Larsson M.H.M.A. 2018. [Left atrial size and contractile function in healthy dogs and dogs with chronic mitral valve disease.] Pesquisa Veterinária Brasileira 38(8):1622-1630. Departamento de Clínica Médica, Faculdade de Medicina Veterinária e Zootecnia, Universidade de São Paulo, Avenida Prof. Dr. Orlando Marques de Paiva 87, São Paulo, SP 05508-270, Brazil. E-mail: lilipetrus@hotmail.com

In humans, left atrial enlargement and reduced contractile functions are associated with adverse cardiovascular events and a poor prognosis in many dilatation of the left atrium occurs with the gradual evolution of chronic mitral valve disease and is well diseases. The left atrium is the most compromised cardiac chamber in dogs with chronic mitral valve disease (CMVD). Therefore, this study aimed to compare the main parameters of left atrial enlargement (left atrium/aorta ratio, left atrial diameter and volume indices) and contractile function (transmitral flow peak velocity A wave and time velocity integral, atrial fraction, and atrial ejection force) at different stages of valve disease, and correlate the left atrial diameter, volume, and contractile function indices with echocardiographic variables predictive of heart failure in dogs (transmitral flow peak velocity $\mathrm{E}$ wave, E wave/IVRT ratio, E wave/E'wave ratio, and $\mathrm{E}$ wave/A wave ratio). The results showed that progressive characterized by the left atrium/aorta ratio and left atrium volume index. The left atrial diameter and volume indices and left atrium/aorta ratio correlated positively with the transmitral flow peak velocity $\mathrm{E}$ wave and $\mathrm{E}$ wave/IVRT ratio, which are important indices of diastolic function. The left atrial contractile function indices increased as CMVD evolved. Except for the atrial fraction, the left atrial contractile function indices correlated with the left ventricular filling pressure indices.
\end{abstract}

INDEX TERMS: Chronic mitral valve disease, heart, dogs, left atrial size, left atrial contractile function, left ventricular filling pressure.

\begin{abstract}
RESUMO.- [Tamanho e função sistólica atrial esquerda em cães sadios e com doença valvar crônica de mitral.] 0 tamanho e a função atrial esquerda estão relacionados em humanos com eventos cardiovasculares adversos e prognóstico nas principais cardiopatias. Na doença valvar crônica de mitral (DVCM) em cães, o átrio esquerdo é a câmara cardíaca mais comprometida. Portanto, os objetivos deste estudo
\end{abstract}

\footnotetext{
${ }^{1}$ Received on June 19, 2017.

Accepted for publication on June 30, 2017.

2 Pesquisadora autônoma, Rua Américo Brasiliense 1349, Apto 104, Chácara Santo Antônio, São Paulo, SP 04715-003, Brazil. *Corresponding author: lilipetrus@hotmail.com

${ }^{3}$ Departamento de Clínica Médica, Faculdade de Medicina Veterinária e Zootecnia, Universidade de São Paulo, Avenida Prof. Dr. Orlando Marques de Paiva 87, São Paulo, SP 05508-270.
}

foram comparar os principais parâmetros de aumento atrial esquerdo (relação átrio esquerdo/aorta, índice do diâmetro atrial esquerdo e índice do volume atrial esquerdo) e função contrátil de átrio esquerdo (velocidade máxima e integral de velocidade da onda A do fluxo transvalvar mitral, fração atrial e força de ejeção atrial) nos diferentes estágios da doença valvar; correlacionar diâmetro e volume atrial esquerdo e os índices de função contrátil atrial esquerda com as variáveis ecocardiográficas preditivas de insuficiência cardíaca em cães (velocidade máxima da onda $\mathrm{E}$ do fluxo transvalvar mitral, relação E/TRIV, relação E/E'par e relação E/A). Os resultados mostraram que com a evolução progressiva da doença valvar crônica de mitral, ocorre dilatação progressiva do átrio esquerdo, bem caracterizada pela relação átrio esquerdo/aorta e pelo índice de volume atrial esquerdo. 0 índice do diâmetro atrial esquerdo, o índice de volume atrial 
esquerdo e a relação átrio esquerdo/aorta correlacionam-se, positivamente, com a velocidade da onda E e com a relação E/TRIV, que são importantes índices de função diastólica. Os índices de função contrátil do átrio esquerdo aumentam à medida que a DVCM evolui. Os índices de função contrátil do átrio esquerdo apresentam correlação positiva com os índices de pressão de enchimento ventricular esquerdo, exceção feita à fração atrial.

TERMOS DE INDEXAÇÃO: Doença valvar crônica, mitral, cardiopatias, cães, tamanho atrial esquerdo, função contrátil atrial esquerda, pressão de enchimento ventricular esquerda.

\section{INTRODUCTION}

Increasing interest has been focused on non-invasive assessments of both size and mechanical function of the left atrium, which can have significant effects on global cardiac performance and cardiovascular morbidity (Triposkiadis et al. 2007). Structurally, the left atrium expands when exposed to increased hemodynamic load conditions (Khoo et al. 2011). Atrial increase, which reflects the chronicity and the severity of the adverse hemodynamic of the left ventricles is associated with cardiovascular events in both humans (Pritchett et al. 2003, Beinart et al. 2004, Leung et al. 2010, Khoo et al. 2011, Yoon et al. 2013) and dogs (Borgarelli et al. 2008, 2012, Schober et al. 2010).

In addition, the left atrium plays an important role in left ventricular filling, and the active or atrial contraction phase provides fundamental compensation for left ventricular compliance, which is reduced in human patients with cardiac failure (Triposkiadis et al. 2007). The preservation of left atrial contraction helps to maintain the ventricular end-diastolic pressure and cardiac output without a significant increase in atrial pressure. However, a reduction in the cardiac contractile function of this chamber induces symptoms of heart failure due to increased left atrial pressure (Triposkiadis et al. 2007). Decreases in echocardiographic indices related to the left atrial function are associated with poor prognosis in human patients with atrial fibrillation after cardioversion (Dogan et al. 2013). Atrial contraction can be evaluated by various indices, such as the transmitral flow A wave peak velocity and velocity time integral (VTI), atrial ejection fraction, and atrial force (Leung et al. 2008). The left atrial fraction (AF) indicates the contribution of atrial to left ventricular filling (Leung et al. 2008). The left atrial force is defined as the force exerted by the atrium to propel blood through the atrioventricular valve during atrial systole (Kiani et al. 2012). These atrial function parameters and left atrial size indices are prognostic markers in several human pathological conditions (Leung et al. 2008).

Chronic mitral valve disease (CVMD) is the most common acquired heart disease observed in small animal practice (Atkins et al. 2009). Studies of dogs with CMVD have shown that an increase in the left atrium can be a strong predictor of congestive heart failure (Schober et al. 2010) and mortality (Borgarelli et al. 2008, 2012).

Most studies conducted in dogs use the left atrial diameter (LAD) to evaluate this cardiac chamber. In contrast, few studies have evaluated the left atrial volume (LAV) as an evaluation method for this heart chamber (Höllmer et al. 2013), although LAV measurement is considered to correlate better with cardiovascular events in humans (Tsang et al. 2006, Leung et al. 2008, Lupu et al. 2014). In addition, no veterinary medicine studies have assessed the left atrial contractile function at different stages of DVCM.

Therefore, we hypothesized that both LAD and LAV would increase with CMVD progression, leading to functional changes that would increase the contractile force and thus overcome the increased left ventricular filling pressure. The objectives of this study were to compare the main parameters of left atrial enlargement (left atrium/aorta ratio [LA/Ao], LAD, and LAV) and left atrial contractile function (transmitral A wave peak velocity and VTI, atrial ejection fraction, and atrial force) at different stages of valvar disease and to correlate the LAD, LAV, and left atrial contractile function indices with echocardiographic variables predictive of heart failure in dogs (transmitral E wave peak velocity, relationship between the mitral valve flow $E$ wave velocity and isovolumetric relaxation time [E/IVRT ratio], relationship between the mitral inflow $\mathrm{E}$ wave velocity and left ventricular free wall base movement $\mathrm{E}^{\prime}$ wave velocity [E/E'pw ratio], and relationship between the velocities of the transmitral flow $\mathrm{E}$ and $\mathrm{A}$ waves [E/A ratio]).

\section{MATERIALS AND METHODS}

\section{Population study}

This study included 40 small and medium-sized dogs of various breeds that attended the Cardiology Service of a Veterinary Hospital. The animals were separated into 4 groups of 10 animals each, according to the classification described in the American College of Veterinary Internal Medicine Consensus Statement (Atkins et al. 2009), as follows:

- Group A/stage A: patients at high risk of developing heart disease, but with no identifiable structural changes indicated by echocardiography;

- Group B1/stage B1: patients with structural heart disease (CMVD) that were asymptomatic and did not present with increased cardiac chambers indicated by echocardiography;

- Group B2/stage B2: patients with structural heart disease (CMVD) that were asymptomatic but presented with increased heart chambers indicated by echocardiography; and

- Group C/stage C: patients with or that presented clinical manifestations related to CMVD, with increased heart chambers indicated by echocardiography.

The animals had previously undergone physical examination, thorax radiography, electrocardiography, and blood pressure measurement. In addition, the animals were subjected to a renal assessment (urinalysis, determination of serum urea and creatinine levels), liver assessment (determination of serum levels of alanine aminotransferase, alkaline phosphatase, total protein, albumin, and bilirubin), complete blood count, and Dirofilaria immitis antigen testing. Animals with diseases of the respiratory tract, kidneys, or liver and those with clinical evidence of endocrine disease were excluded from the study. Animals that were also excluded: those that had been previously treated or were currently receiving treatment involving positive inotropic substances (pimobendan and digitalis); those diagnosed with congenital heart disease, acquired cardiomyopathies, 
or supraventricular or ventricular tachyarrhythmias; and those with systemic arterial hypertension.

\section{Echocardiography}

Echocardiographic examinations was performed using an ultrasound device (VIVID I®; GE Medical Systems, Waukesha, WI, USA) equipped with 2-dimensional (2D), 1-dimensional (M), and Doppler (pulsed, color, continuous, and tissue Doppler) modes and 2 sectorial multifrequency transducers $(2.9-4.0 \mathrm{MHz}$ and 5.0-8.0 MHz), according to the recommendations of the Echocardiography Committee of Specialty of Cardiology, American College of Veterinary Internal Medicine (Thomas et al. 1993), American Society of Echocardiography (Boon 1998a), and other consulted authors (Bonagura 1983, 1994, Boon 1998b, Moïse \& Fox 1999, Bonagura \& Fuentes 2004). Echocardiographic images were saved in digital format, and the results were analyzed on the same device at a later time. Three consecutive measurements were made for each analyzed variable, and a mean value was obtained and considered for further evaluation.

The animals were positioned in the left lateral recumbancy position with the transducer placed on the chest; in this position, image analysis were performed through the right parasternal window and cranial and caudal left parasternal windows. Animals with no valvar changes were placed in group A. Patients with nodular mitral valve leaflet lesions characteristic of degenerative injury on 2-dimensional imaging and mitral valve insufficiency, characterized as turbulent systolic flow in the left atrium and detected by color or pulsed Doppler (Chetboul \& Tissier 2012), were allocated to other groups according to echocardiographic and clinical characteristics.

Left atrial enlargement was defined as an LA/Ao $>1.50$ as measured in the 2-dimensional mode with a short axis view and right parasternal window, just before ventricular contraction (ECG QRS complex) (Borgarelli et al. 2008).

Left ventricle diastolic function. Left ventricular diastolic function was assessed using mitral valve flow echocardiographic variables ( $\mathrm{E}$ wave velocity, A wave velocity and $\mathrm{E} / \mathrm{A}$ ratio), IVRT, E/IVRT ratio, and E/E'pw ratio. Mitral flow spectrum was obtained using an apical 4-chamber view and caudal left parasternal window. Sample volume of pulsed Doppler was positioned immediately after the opening point of the valve leaflets, inside the left ventricle. Subsequently, using the electrocardiographic tracing as a reference, the following measures were taken:

- Mitral valve flow E wave peak velocity (E wave): Spectrum formed soon after the end of ventricular contraction (ECG T wave);

Mitral valve flow A wave peak velocity (A wave): Spectrum formed soon after the onset of atrial contraction (after the ECG P wave)

- Mitral valve inflow E/A ratio;

Transmitral velocity integral time: defined as the area below the mitral inflow, or the distance traveled by the blood (in $\mathrm{cm}$ ), which was obtained from the contour of the analyzed spectrum and calculated automatically using software installed in the echocardiographic equipment.

In addition to these variables, the apical 4-chamber mode and left parasternal window were used to obtain the $E^{\prime}$ wave peak velocity of the movement of the left ventricle free wall (E'pw), positioning the sample volume of the pulsed tissue Doppler on the posterior wall of the left ventricle, near the insertion of the mitral leaflets. The spectrum that formed shortly after the end of the ventricular contraction (ECG T wave) was considered the E'pw. The E/E'pw ratio was calculated using this parameter.

By positioning the sample volume of pulsed Doppler between left ventricular inflow and outflow tract, it was obtained the spectra of mitral inflow and left ventricular outflow. The time between the end of the aortic flow and beginning of the mitral inflow was defined as isovolumetric relaxation time (IVRT), and it was used to calculate the E/IVRT ratio.

Left atrial diameter, volume and systolic function. The LAD was measured using a longitudinal left ventricular outflow tract view, the left parasternal window, and 1-dimensional mode while positioning the cursor line on the aortic valve and the left atrium at the point of the greatest LAD during ventricular systole (Fig.1). This measure was corrected to the body surface area (BSA) (Jacobs \& Mahjoob 1988) to obtain the LAD index (LADi, in $\mathrm{cm} / \mathrm{m}^{2}$ ).

The maximum LAV (LAV max) was obtained using the apical 4-chamber view and left parasternal window according to the following area-length method equation (Lang et al. 2005):

$$
\text { LAV Max: } 8 / 3 \pi(\mathrm{LAA} / \mathrm{LAL})=(0.85 \times \mathrm{LAA}) / \mathrm{LAL}
$$

Where LAA and LAL are the left atrial area and length, respectively. To obtain the LAA, the edge of the left atrium was plotted along the left atrial inner wall, starting at the insertion site of the parietal leaflet of the mitral valve and ending at the insertion of the septal leaflet but excluding the confluence of the pulmonary veins (Fig.2). Next, LAL was measured from the center of mitral annular ring plane to the top edge of the left atrium. These measurements were performed immediately before mitral valve opening, and both measurements used a cineloop, which allowed return of the image to the desired movement point. This measurement was also corrected for the BSA (Jacobs \& Mahjoob 1988) to obtain the LAV index (LAVi Max $/ \mathrm{m}^{2}$, in $\mathrm{ml}$ ).

Using an apical 4-chamber view and the left parasternal window, mitral valve flow A wave peak velocity and its VTI were measured. The latter was measured by determining the area under the mitral wave, or the distance traveled by the blood (in $\mathrm{cm}$ ), which was obtained from the contour of the analyzed spectrum and calculated automatically using software installed in the echocardiography equipment.

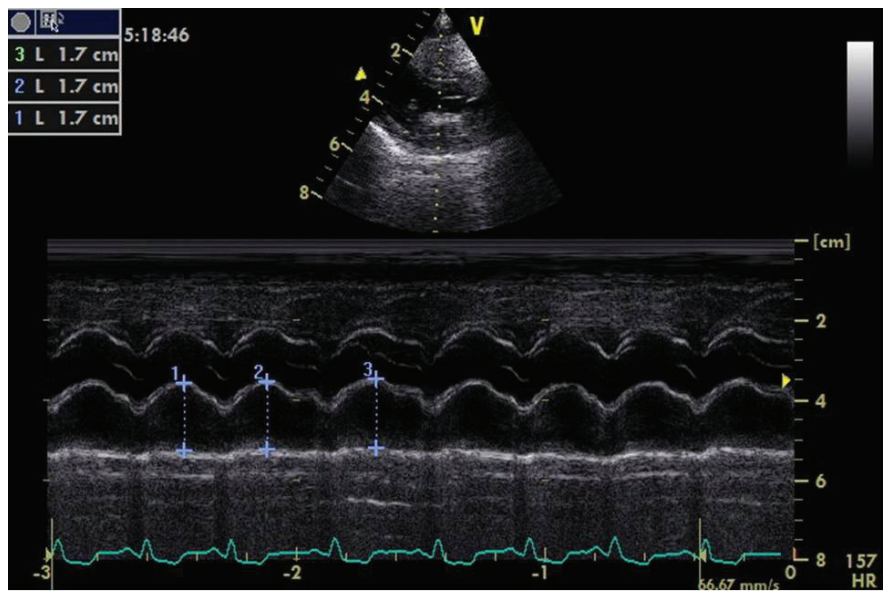

Fig.1. Echocardiographic image, 1-dimensional mode, longitudinal left ventricular outflow tract view, left parasternal window. The numbers 1, 2 and 3 indicate the maximum left atrial diameter measurements. Source: Cardiology Service of the Veterinary Hospital of the University of São Paulo. 


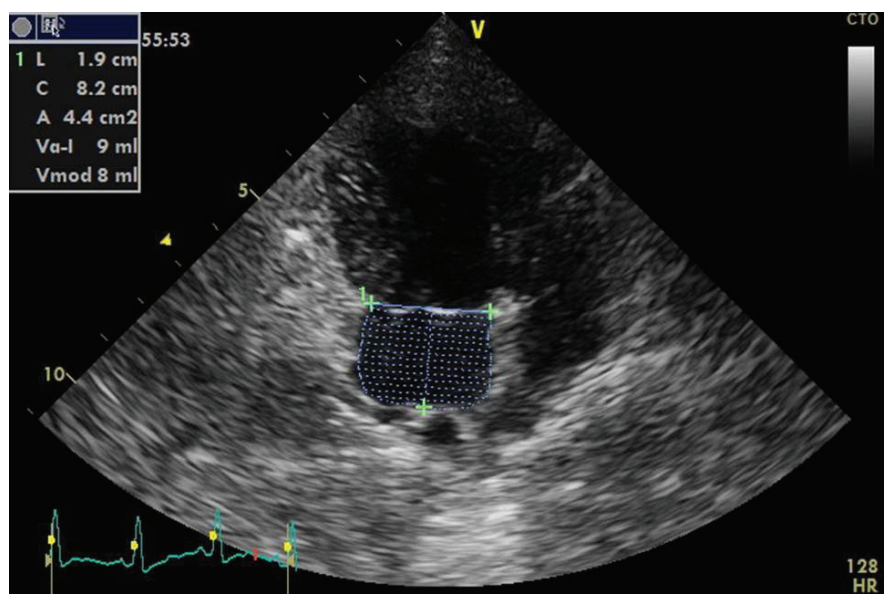

Fig.2. Echocardiographic image, 2-dimensional mode, apical 4-chamber view, left parasternal window. Maximum left atrial volume measurement using the area-length method (Lang et al. 2005). The edge of the left atrium is plotted along the left atrial inner wall (excluding the confluence of the pulmonary veins), starting at the insertion site of the parietal leaflet of the mitral valve and ending at the insertion of the septal leaflet; LAA was obtained in this manner. LAL was measured from the center of the mitral annular ring plane to the top edge of the left atrium. Source: Cardiology Service of the Veterinary Hospital of the University of São Paulo.

The left AF was calculated by dividing the A wave VTI by the total transmitral flow VTI (Leung et al. 2008). The left atrium ejection force (LAEF) was determined according to the method described by Manning et al. (1993), using the equation:

$$
\text { LAEF }(\text { kdynes })=0.5 \times \rho \times \text { mitral area } \times(\text { A wave })^{2}
$$

where $\rho$ is the density of blood $\left(1.06 \mathrm{mg} / \mathrm{cm}^{3}\right)$, mitral area is the area of the mitral valve orifice $\left(\mathrm{cm}^{2}\right)$, and $A$ wave is the mitral valve flow A wave peak velocity ( $\mathrm{cm} / \mathrm{s}$ ). The mitral valve orifice area was determined using the formula $\pi \mathrm{xd}^{2} / 4$, where $\mathrm{d}$ is the distance between the insertion points of the leaflets as measured in the apical 4-chamber view, assuming that the valve ring format is circular. This value was then corrected for the BSA (Jacobs \& Mahjoob 1988) to obtain the LAEF index (LAEFi, in Kdynes $/ \mathrm{m}^{2}$ ).

\section{Statistical analysis}

All variables were subjected to the Anderson-Darling test to evaluate the normality of distribution The means of normally distributed variables (body surface area, A wave, A wave VTI, atrial fraction, IVRT, E wave, E/IVRT, E' wave, and mitral VTI) were compared using one way analysis of variance (ANOVA) and a Tukey's post hoc test. The medians of non-normally distributed variables (LADi, LAVi max, LAEF, E/E', E/A, mitral area, and LA/Ao ratio) were compared using the Kruskal-Wallis test with Dunn's post-test. A p value of $<0.05$ was used to define statistical significance. To evaluate the associations between variables representing the left atrial function (LAVi max, LADi, -LA/Ao, AF, LAEF, A wave, and A wave VTI) and those representing the diastolic function (E wave, E/IVRT, E/E', and $\mathrm{E} / \mathrm{A}$ ratio), the correlation coefficients were determined using the Pearson (variables with parametric distribution) or Spearman test (variables with non-parametric distribution). Again, a p value of $<0.05$ was used to define statistical significance.

\section{RESULTS}

The following 40 small or medium-sized dogs were evaluated: 15 poodles, 14 mongrel dogs (of undefined breed), 4 Shih Tzus, 2 Pinschers, 1 Yorkshire terrier, 1 Maltese, 1 Beagle, 1 Dachshund, and 1 Lhasa Apso. Twenty-three dogs were male (57.5\%), and 17 were female (42.5\%). The BSA ranged from $0.20-0.65 \mathrm{~m}^{2}$, with an average of $0.35 \pm 0.11 \mathrm{~m}^{2}$. There were no significant differences between the groups in terms of BSA $(p=0.109)$ and gender $(\mathrm{p}=0.350)$.

Regarding age, the control animals $(5.4 \pm 1.83$ years $)$ were younger $(\mathrm{p}<0.0001)$ than those in the B1 ( $9.44 \pm 2.29$ years), B2 (11.33 \pm 3.42 years), and C groups (10.8 \pm 2.04 years).

Three animals in the $\mathrm{B} 2$ group were treated with benazepril. In Group C, 4 animals were receiving treatment with the following drugs at the time of the echocardiogram study: enalapril, hydralazine, furosemide, and spironolactone $(n=1)$; benazepril, furosemide, and spironolactone $(n=1)$; enalapril and spironolactone $(n=1)$; and enalapril, furosemide, and spironolactone $(n=1)$.

The analyzed echocardiographic variables are shown in Table 1.

Positive and significant correlation was observed between the variables used to estimate left atrial function (LAVi max, LADi, LA/Ao, LAEF, A wave, and A wave VTI) and those used to estimate diastolic function (E/E' and $E / A)$, whereas the $\mathrm{E} / \mathrm{A}$ ratio was found to associate negatively with the AF, LAEF, A wave, and A wave VTI (Table 2).

\section{DISCUSSION}

Left atrium is the first cardiac chamber affected by CMVD, and studies of dogs with this disease have shown that an increase in the size of this heart chamber is strongly predictive of congestive heart failure (Schober et al. 2010) and mortality (Borgarelli et al. 2008, 2012). Previous study of dogs diagnosed with CMVD found a negative correlation between the LAEF, measured by 3-dimensional echocardiography, and the left atrial size, indicating that stretching decreases the contractile capacity of myocytes (Tidholm et al. 2013). The decreased left atrial contractile ability associated with left atrial and ventricular volume overload can contribute to decreases in the stroke volume and cardiac output and thus influence the clinical decisions of veterinary medical professionals, such as those concerning the use of positive inotropic drugs.

In humans, the left atrium increases under conditions of pressure overload, such as mitral stenosis, increased left ventricular filling pressure, and conditions of volume overload such as mitral regurgitation, an increased cardiac output state, shunts, and fistulas (To et al. 2011). Previous study in humans showed that LAD, measured using 1-dimensional mode, LAA, and LAV were predictive of cardiovascular events such as atrial fibrillation, transient ischemia, acute myocardial infarction, congestive heart failure, and sudden death (Tsang et al. 2006). Among these 3 factors, however, LAV exhibited the best predictive performance. Other studies in humans have shown that LAVi is an important predictive factor of cardiovascular events (Pritchett et al. 2003, Leung et al. 2010) and prognosis (Beinart et al. 2004, Yoon et al. 2013).

In the present study, 3 methods were used to assess the left atrial size: LAD and LAV, which were both adjusted for the BSA, and LA/Ao. LA/Ao was higher in stage B2 and 
Table 1. Echocardiographic variables evaluated in healthy dogs affected with CMVD at different stages (B1, B2, and C) according to Atkins et al. (2009)

\begin{tabular}{|c|c|c|c|c|c|}
\hline Variable & Control & B1 & B2 & $\mathrm{C}$ & $\mathrm{P}$ value \\
\hline $\mathrm{N}$ & 10 & 10 & 10 & 10 & - \\
\hline HR & $120 \pm 18.99$ & $108 \pm 36.25$ & $106 \pm 32.21$ & $128 \pm 36.25$ & 0.3878 \\
\hline LA/Ao & $1.11(0,94-1.37)^{\mathrm{b}}$ & $1.28(0.93-1.49)^{\mathrm{b}}$ & $1.74(1.48-2.07)^{\mathrm{a}}$ & $2.18(1.62-3.35)^{\mathrm{a}}$ & $<0.0001$ \\
\hline LAVi max & $13.25(10.16-19.81)^{c}$ & $20.71(13.73-28.06)^{\mathrm{bc}}$ & $36.65(16.09-44.37)^{\mathrm{ab}}$ & $66.63(27.37-215.95)^{\mathrm{a}}$ & $<0.0001$ \\
\hline Mitral area & $2.01(1.41-4.79)^{\mathrm{b}}$ & $3.22(1.70-4.30)^{\mathrm{ab}}$ & $3.00(2.06-3.70)^{\mathrm{ab}}$ & $3.31(2.16-6.16)^{\mathrm{a}}$ & 0.022 \\
\hline $\mathrm{AF} \%$ & $0.21 \pm 0.04^{\mathrm{b}}$ & $0.37 \pm 0.07^{a}$ & $0.48 \pm 0.11^{\mathrm{a}}$ & $0.38 \pm 0.12^{\mathrm{a}}$ & $<0.0001$ \\
\hline LAEF & $3.48(1.94-7.68)^{\mathrm{b}}$ & $5.30(2.16-9.07)^{\mathrm{ab}}$ & $10.69(3.42-20.98)^{\mathrm{a}}$ & $10.19(4.13-25.86)^{\mathrm{a}}$ & 0.0001 \\
\hline E wave $(\mathrm{m} / \mathrm{s})$ & $0.76 \pm 0.08^{\mathrm{bc}}$ & $0.63 \pm 0.11^{\mathrm{c}}$ & $0.86 \pm 0.18^{\mathrm{b}}$ & $1.17 \pm 0.24^{\mathrm{a}}$ & $<0.0001$ \\
\hline A wave $(\mathrm{m} / \mathrm{s})$ & $0.56 \pm 0.08^{\mathrm{b}}$ & $0.56 \pm 0.10^{\mathrm{b}}$ & $0.78 \pm 0.22^{\mathrm{a}}$ & $0.78 \pm 0.16^{\mathrm{a}}$ & 0.001 \\
\hline E/A ratio & $1.28(1.18-1.91)^{\mathrm{a}}$ & $1.16(0.81-1.60)^{\mathrm{a}}$ & $1.14(0.71-1.40)^{\mathrm{a}}$ & $1.30(1.04-3.21)^{\mathrm{a}}$ & 0.023 \\
\hline
\end{tabular}

Different letters in the same line represent a statistically significant difference ( $\mathrm{p}<0.05)$. The parametric variables (body surface area, A wave, A wave VTI, atrial fraction, IVRT, E wave, E/IVRT, E pw 'and mitral wave VTI) were compared using an analysis of variance and Tukey's post-test and are presented as means and standard deviations; non-parametric variables (LADi, LAVi max, LAEF, E/E'pw, E/A, mitral area and LA/Ao ratio) were compared using the Kruskal-Wallis test and Dunn's post-test, and are presented as medians with minimum and maximum values. CMVD $=$ chronic mitral valvar disease, $\mathrm{HR}=$ heart rate, $\mathrm{E} / \mathrm{IVRT}$ ratio = relationship between the mitral valve flow $\mathrm{E}$ wave velocity and isovolumetric relaxation time, $\mathrm{E} / \mathrm{E}$ 'pw ratio $=$ relationship between the mitral inflow flow $\mathrm{E}$ wave velocity and left ventricular free wall base movement $\mathrm{E}^{\prime}$ wave velocity, E/A ratio = relationship between the velocities of the transmitral flow $\mathrm{E}$ and $\mathrm{A}$ waves, $\mathrm{LA} / \mathrm{Ao}$ ratio $=$ relationship between the left atrial and aortic diameters, IVRT $=$ isovolumetric relaxation time index, LADi = left atrial diameter index, LAVi max = maximum left atrial volume index, AF = atrial fraction, LAEF = left atrial ejection force, $\mathrm{LAEFi}=$ left atrial ejection force index, VTI = velocity time integral.

Table 2. Correlation between echocardiographic variables representative of left atrial function (LAVi max, atrial fraction, LAEF, A wave and VTI A) and of diastolic function (E wave, E/IVRT, E/E'pw and E/A ratio)

\begin{tabular}{|c|c|c|c|c|}
\hline \multirow{2}{*}{ Atrial function } & \multicolumn{4}{|c|}{ Diastolic function } \\
\hline & E wave & E/IVRT & E/E'pw & $\mathrm{E} / \mathrm{A}$ \\
\hline LAVi max & $\rho=0.64, p<0.0001$ & $\rho=0.125, p<0.0001$ & NS & NS \\
\hline LADi & $\rho=0.57, \mathrm{p}<0.0001$ & $\rho=0.49, p=0.001$ & $\rho=0.48, p=0.002$ & NS \\
\hline LA/Ao & $\rho=0.64, p<0.0001$ & $\rho=0.59, \mathrm{p}<0.0001$ & $\rho=0.46, p=0.003$ & NS \\
\hline Atrial fraction & NS & NS & NS & $\rho=-0.49, p=0.001$ \\
\hline LAEF & $\rho=0.62 p<0.0001$ & $\rho=0.54, p<0.0001$ & NS & $\rho=-0.32, p=0.03$ \\
\hline A wave & $\mathrm{r}=0.47, \mathrm{p}=0.002$ & NS & $\rho=0.42, p=0.007$ & $\rho=-0.35, p=0.02$ \\
\hline VTI A & $r=0.43, p=0.006$ & NS & NS & $\rho=-0.37, p=0.01$ \\
\hline
\end{tabular}

Level of statistical significance, 5\%; NS = not significant, $r=$ Pearson coefficient, $\rho=$ Spearman coefficient, E/IVRT = relationship between the mitral valve flow $\mathrm{E}$ wave velocity and isovolumetric relaxation time, $\mathrm{E} / \mathrm{E}^{\prime} \mathrm{pw}=$ relationship between the mitral inflow flow $\mathrm{E}$ wave velocity and left ventricular free wall base movement $\mathrm{E}^{\prime}$ wave velocity, $\mathrm{E} / \mathrm{A}=$ relationship between the velocities of the transmitral flow $\mathrm{E}$ and $\mathrm{A}$ waves, $\mathrm{LAD}=$ left atrial diameter, LADi $=$ left atrial diameter index, LAV = left atrial volume, LAVi max = maximum left atrial volume index, LAEF $=$ left atrial ejection force, $\mathrm{VTI}=$ velocity time integral.

C patients than in stage A and B1 patients (Fig.3). This result was expected, as this parameter was used to distinguish patients with and without left atrial enlargement. The results obtained herein were similar to those obtained for the LAVi max, which increased progressively with each CMVD functional class, and the $\mathrm{C}$ group had a statistically higher LAVi than did the A and B1 groups (Fig.4). However, LADi only differed significantly between groups B1 and C. One possible explanation is that LAD measurements in the 1-dimensional mode only measure the anteroposterior diameter and thus fail to account for possible increases in the craniocaudal and medial-lateral axes of this heart chamber. According to Khoo et al. (2011), in humans the left atrium is compressed above by the aortic arch and, later, the tracheal bifurcation; therefore, changes in the anterior-posterior diameter might not be proportional and could underestimate changes in the LAD.

In human medicine, echocardiographers prefer to use area and volume measurements to determine left atrium dimensions, as these correlate better with increased risk of cardiovascular events (Tsang et al. 2006, Leung et al. 2008, 


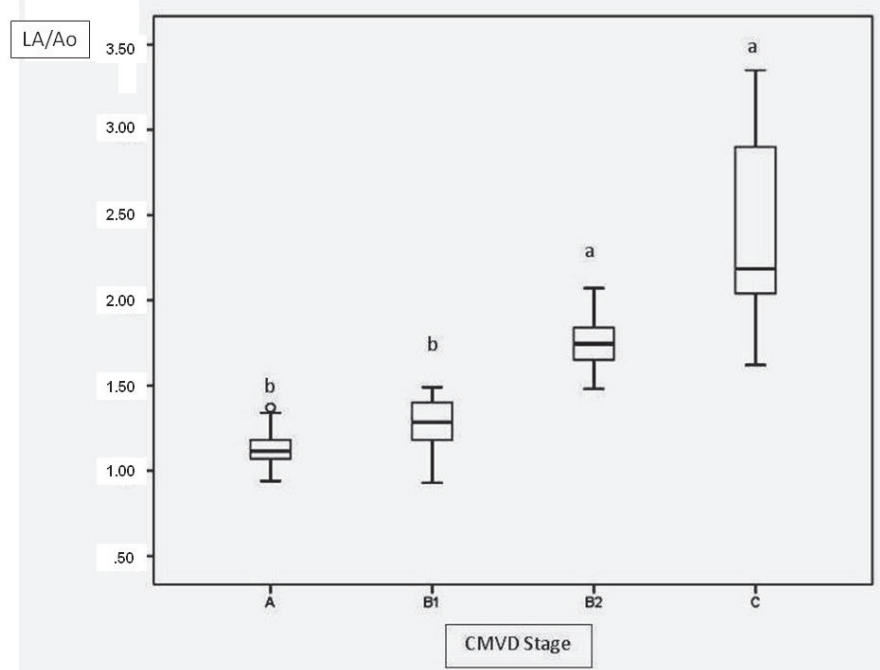

Fig.3. Left atrium/aortic ratio (LA/Ao) values at different stages of valvar disease. Different letters indicate statistically significant differences $(\mathrm{p}<0.0001)$.

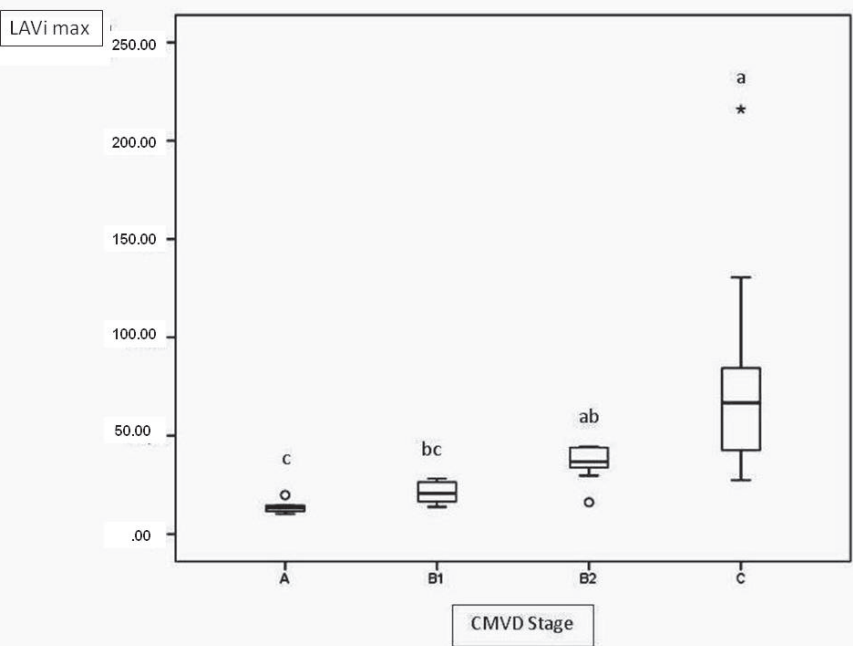

Fig.4. Maximum left atrial volume index (LAVI max) values at different stages of valvar disease. Different letters indicate statistically significant differences $(\mathrm{p}<0.0001)$.

Lupu et al. 2014). For this reason, the present study evaluated the correlation between LAVi and variables related to increased left ventricular filling pressure. Studies of dogs diagnosed with CMVD demonstrated the strong predictive value of echocardiographic variables of diastolic function, such as the mitral valve flow $\mathrm{E}$ wave velocity, transmitral $\mathrm{E} / \mathrm{A}$ ratio (Tidholm et al. 2009, Schober et al. 2010), E/IVRT ratio (Schober et al. 2010), and E/E'pw ratio (Bruch et al. 2004, Schober et al. 2010), with regard to the development of congestive heart failure. In the present study, symptomatic patients (group C) had an increased E wave velocity and higher E/E'pw and E/IVRT ratios when compared to asymptomatic patients (B1 and B2). LAVi exhibited moderate positive correlation with the E wave velocity (Fig.5) and weak positive correlation with E/IVRT ratio. An increase in LAV leads to increased left atrial pressure, which promotes increased diastolic flow velocity

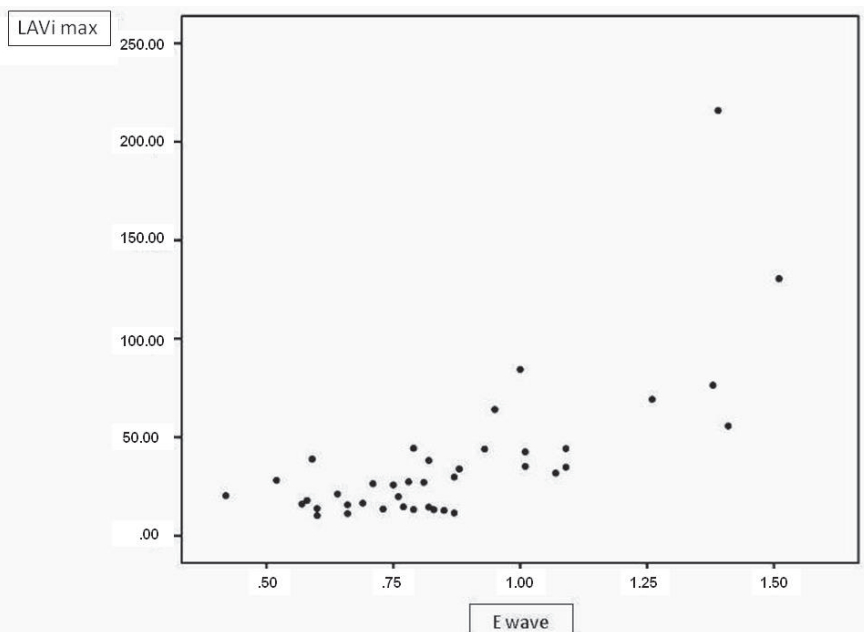

Fig.5. Correlation between the maximum left atrial volume index (LAVI max) and mitral inflow $E$ wave velocity. $\rho=0.64 ; p<0.0001$.

in early diastole and early opening of mitral valve, thereby shortening the isovolumetric relaxation period. Contrary to our expectations, the E/E'pw did not change with increase in LAV. Despite the increase in mitral $\mathrm{E}$ wave velocity as the LAV increased, the E'pw wave remained unchanged despite disease progression. In healthy dogs, the E'pw wave velocity is known to depend on load (or volume) received by the left ventricle during relaxation (Schober et al. 2010). The absence of primary diastolic abnormalities in myocardial relaxation and/or ventricular compliance, typically seen in dogs with CMVD, might explain why E'pw wave velocity did not change as the LAV increased, which limited the use of E/E' ratio as a left ventricular filling pressure index. Similar to the LAVi, other left atrial size parameters as LADi and LA/Ao ratio (Fig.6) exhibited moderate positive correlations with the $\mathrm{E}$ wave velocity and weak positive correlations with the E/IVRT ratio. In addition, these left atrial diameter parameters exhibited weak positive correlations with E/E'pw ratio.

Besides the above-mentioned importance of the increase in left atrial size with respect to the development of cardiovascular adverse effects and prognosis, preservation of the cardiac chamber contraction helps to maintain the end-diastolic left ventricular pressure and heart rate without a significant increase in the left atrial pressure. In contrast, in humans, left atrial failure can develop into heart failure as a result of the high pressure inside this cardiac chamber (Triposkiadis et al. 2007). In this study, left atrial contractile function was assessed using the maximum velocity and velocity time integral of the transmitral flow A wave, AF, and LAEF.

The A wave velocity has been used for serial evaluation of human patients with atrial fibrillation after cardioversion (Leung et al. 2008, To et al. 2011). Atrial fraction, which is the ratio of A wave velocity time integral to total diastolic mitral valve flow velocity time integral, are also used as left atrial function parameters in human cardiology (Leung et al. 2008). In the present study, transmitral A wave velocity was higher in dogs with left atrial enlargement (B2 groups and C) than in those without left atrial enlargement (groups A and B1). Transmitral A wave VTI tended to exhibit a progressive increase according to the valvar disease stage (i.e., higher 


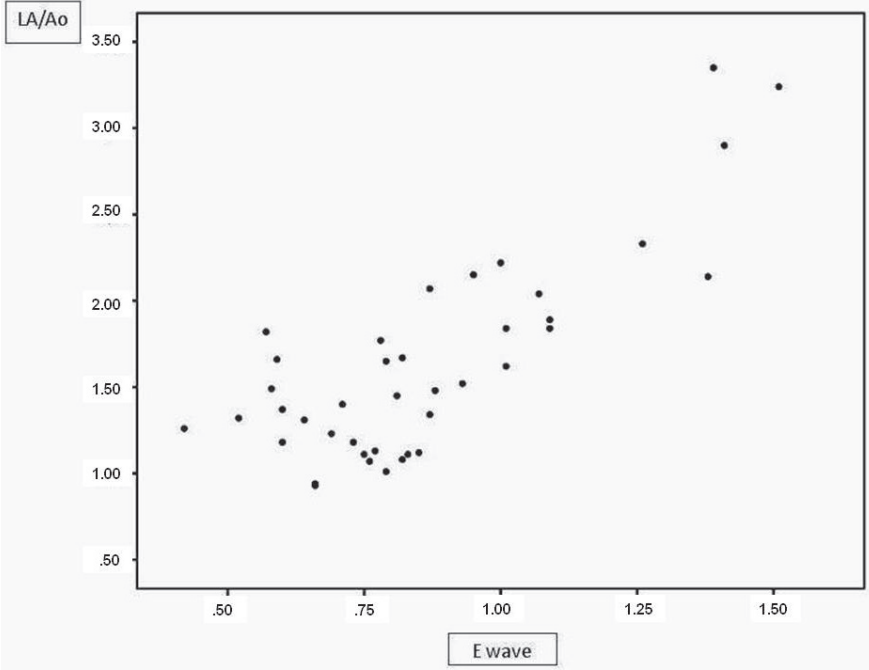

Fig.6. Correlation between the left atrium/aorta ratio (LA/Ao) and mitral inflow E wave velocity. $\rho=0.64 ; p<0.0001$.

values in groups $\mathrm{B} 2$ and $\mathrm{C}$ than in groups $\mathrm{A}$ and $\mathrm{B} 1)$. A wave velocity and VTI correlated positively with the $\mathrm{E}$ wave and negatively with $\mathrm{E} / \mathrm{A}$ ratio. Left AF, or the extent by which atrial contraction contributes to left ventricular filling, did not differ significantly between patients at different stages of valve disease, indicating that despite the evolution of valvular heart disease, the LAEF did not appear to be damaged. Assuming preserved ventricular compliance, this can be explained by a lack of opposition to contraction of the left atrium, which manages to maintain its role in left ventricular filling.

The LAEFi is defined as the force exerted by the atrium to propel blood through the atrioventricular valve during atrial systole (Kiani et al. 2012). In fact, the LAEF represents the percentage of atrial contribution to the diastolic performance of the heart and, in humans, is considered to correspond to early diastolic dysfunction of the ventricles that cannot be detected via conventional methods of diastolic function assessment (Kiani et al. 2012). In this study, the LAEFi was higher in patients with left atrial enlargement, compared to healthy dogs (Fig.7), suggesting that greater efforts were required to maintain a near-normal left ventricle filling pressure. In addition, left atrial enlargement is accompanied by dilation of the mitral valve annulus and a consequent increase in the mitral valve area, which increases the calculated LAEF. No statistically significant difference in LAEFi was observed between the animals in groups B2 and C. These findings are similar to those of Triposkiadis et al. (2007), who obtained higher LAEF values in human patients with heart failure relative to those in healthy hearts. In the present study, LAEFi showed moderate positive correlation with $\mathrm{E}$ wave velocity (Fig.8), as well as the E/IVRT, and a negative correlation with $\mathrm{E} / \mathrm{A}$ ratio. These findings are similar to those obtained in human patients with myocardial infarction compared to healthy patients (Dogan et al. 2013), and indicate that, with increasing left ventricular filling pressure, left atrium exerts more force to propel the blood. In human medicine, the reduction of LAEF is a poor prognostic factor because it indicates left atrial failure secondary to a significant increased pressure inside this heart chamber (Dogan et al. 2013).

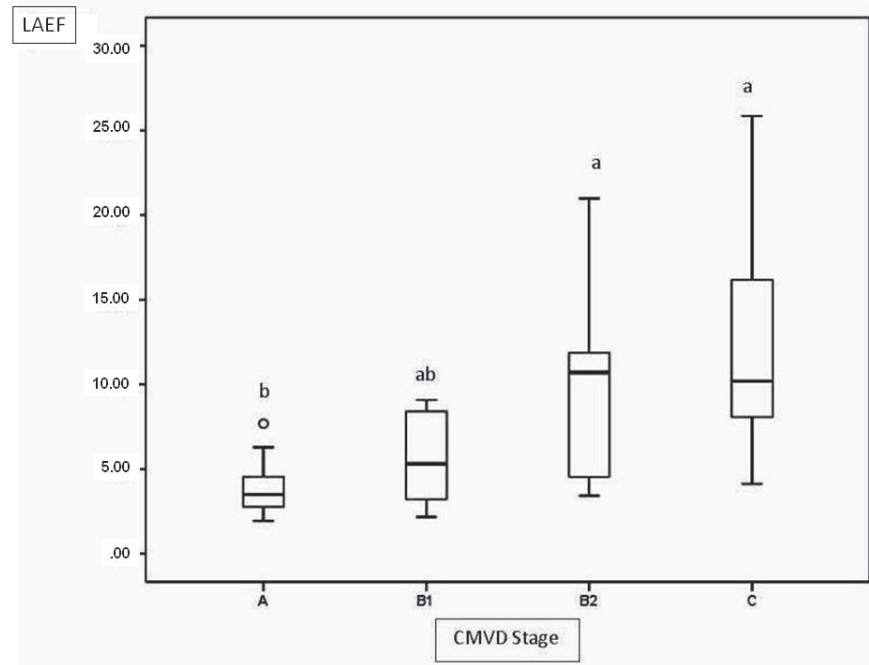

Fig.7. Left atrial ejection force at different stages of valvar disease. Different letters indicate statistically significant differences $(p=0.0001)$.

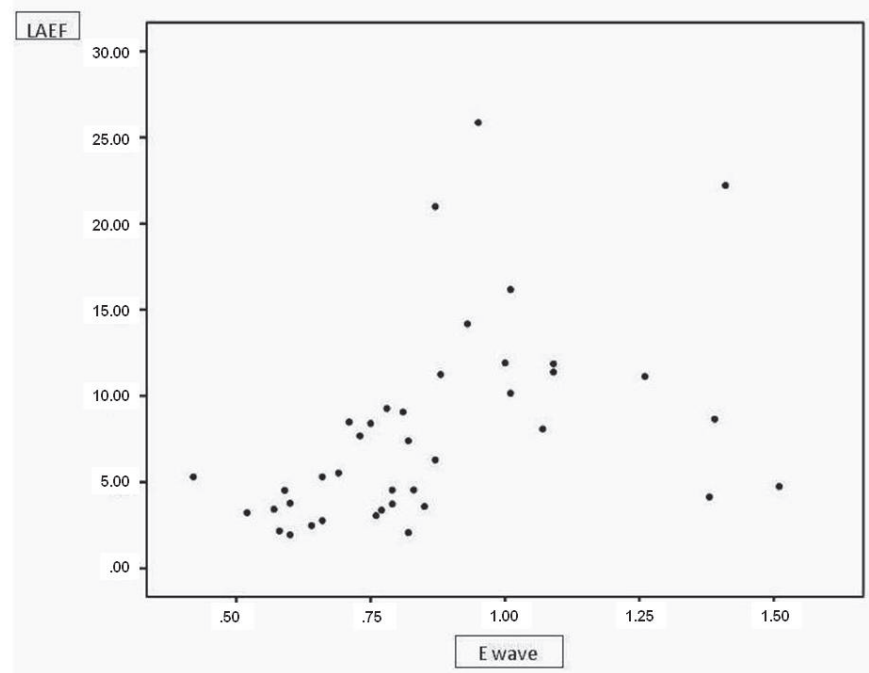

Fig.8. Correlation between the left atrial ejection force and mitral valve flow $\mathrm{E}$ wave velocity. $\rho=0.62 ; \mathrm{p}<0.0001$.

One limitation of the present study was the absence of patients with stage D of CMVD. These dogs were excluded because most were receiving treatment with positive inotropic drugs, which might affect assessments of left atrial systolic function. The use of diuretics and angiotensin converting enzyme inhibitors, especially in stage C patients, may affect left ventricular filling pressures and after-load, and should also be considered a limitation of the present study. Therefore, further studies involving dogs with stage D CMVD are needed to clarify whether significant changes in the left atrial contractile function parameters are apparent at that stage. In addition, the noted differences in age among the animals in this study, especially between the control group and CMVD groups, might have affected the expected results. Previous study conducted with healthy dogs and those with CMVD found that the LAEF (measured using 3-dimensional 
echocardiography) decreases with age, likely due to reduced left ventricular compliance and consequent increase in left atrial afterload (Tidholm et al. 2013). Finally, it is not known whether breed affects left atrial contractile function; rather, only an increase in body weight has been shown to cause decrease in LAEF (Tidholm et al. 2013). Therefore, future research should investigate the influence of breed on LAEF.

\section{CONCLUSIONS}

This study has demonstrated progressive dilation of the left atrium with gradual CMVD evolution, which was well characterized by the LA/Ao ratio and the LAVi. LAVi, LADi, and LA/Ao ratio correlated positively with the E wave velocity and the E/IVRT ratio, which are important diastolic function indices.

The left atrial contractile function rates also increased as CMVD evolved. Except for AF, left atrial contractile function indices were found to correlate positively with ventricular filling pressure.

\section{REFERENCES}

Atkins C., Bonagura J., Ettinger S., Fox P., Gordon S., Haggstrom J., Hamlin R., Keene B., Luis-Fuentes V. \& Stepien R. 2009. Guidelines for the diagnosis and treatment of canine chronic valvular heart disease. J. Vet. Intern. Med. 23(6):1142-1150. <http://dx.doi.org/10.1111/j.1939-1676.2009.0392. $\mathrm{x}><$ PMid:19780929>

Beinart R., Boyko V., Schwammenthal E., Kuperstein R., Sagie A., Hod H., Matetzky S., Behar S., Eldar M. \& Feinberg M.S. 2004. Long-term prognostic significance of left atrial volume in acute myocardial infarction. J. Am. Coll. Cardiol. 44(2):327-334. <http://dx.doi.org/10.1016/j.jacc.2004.03.062> $<$ PMid:15261927>

Bonagura J.D. 1983. M-mode echocardiography. Vet. Clin. N. Am. Small Anim. Pract. 13(2):299-319. <http://dx.doi.org/10.1016/S0195-5616(83)500314> <PMid:6604983>

Bonagura J.D. 1994. Echocardiography. J. Am. Vet. Med. Assoc. 204(4):516522. <PMid:8163410>

Bonagura J.D. \& Fuentes V.L. 2004. Ecocardiografia, p.884-925. In: Ettinger S.J. \& Feldman E.C. (Eds), Tratado de Medicina Interna Veterinária. Guanabara Koogan, Rio de Janeiro.

Boon J.A. 1998a. Evaluation of size, function, and hemodynamics, p.151-260. In: Boon J.A. (Ed), Manual of Veterinary Echocardiography. Williams and Wilkins, Baltimore, USA.

Boon J.A. 1998b. The echocardiographic examination, p.35-150. In: Boon J.A. (Ed), Manual of Veterinary Echocardiography. Williams and Wilkins, Baltimore, USA.

Borgarelli M., Crosara S., Lamb K., Savarino P., La Rosa G., Tarducci A. \& Haggstrom J. 2012. Survival characteristics and prognostic variables of dogs with preclinical chronic degenerative mitral valve disease attributable to myxomatous degeneration. J. Vet. Intern. Med. 26(1):69-75. <http://dx.doi. org/10.1111/j.1939-1676.2011.00860.x> <PMid:22211523>

Borgarelli M., Savarino P., Crosara S., Santilli R.A., Chiavegato D., Poggi M., Bellino C., La Rosa G., Zanatta R., Haggstrom J. \& Tarducci A. 2008. Survival characteristics and prognostic variables of dogs with mitral regurgitation attributable to myxomatous valve disease. J. Vet. Intern. Med. 22(1):120-128. <http://dx.doi.org/10.1111/j.1939-1676.2007.0008.x><PMid:18289298>

Bruch C., Stypmann J., Gradaus R., Breithardt G. \& Wichter T. 2004. Usefulness of tissue Doppler imaging for estimation of filling pressures in patients with primary or secondary pure mitral regurgitation. Am. J. Cardiol. 93(3):324-328. <http://dx.doi.org/10.1016/j.amjcard.2003.10.012> $<$ PMid:14759382>
Chetboul V. \& Tissier R. 2012. Echocardiographic assessment of canine degenerative mitral valve disease. J. Vet. Cardiol. 14(1):127-148. <http:// dx.doi.org/10.1016/j.jvc.2011.11.005> <PMid:22366573>

Dogan C., Omaygenc O., Hatipoglu S., Bakal R.B., Demirkiran A., Emiroglu M.Y., Bayram T. \& Ozdemir N. 2013. Assessment of ST-elevation myocardial infarction-related diastolic dysfunction with compensatory rise in left atrial ejection force. Echocardiography 30(3):279-284. <http://dx.doi. org/10.1111/echo.12048><PMid:23186322>

Höllmer M., Willesen J.L., Tolver A. \& Koch J. 2013. Left atrial volume and phasic function in clinically healthy dogs of 12 different breeds. Vet. J. 197(3):639645. <http://dx.doi.org/10.1016/j.tvjl.2013.05.045><PMid:23838204>

Jacobs G. \& Mahjoob K. 1988. Multiple regression analysis, using body size and cardiac cycle length, in predicting echocardiographic variables in dogs. Am. J. Vet. Res. 49(8):1290-1294. <PMid:3178024>

Kiani A., Shabanian R., Rekabi M., Kocharian A. \& Heidari-Bateni G. 2012. Assessment of left atrial ejection force in mildly asphyxiated newborns. Iran. J. Pediatr. 22(4):519-523. <PMid:23430476>

Khoo C.W., Krishnamoorthy S., Lim H.S. \& Lip G.Y. 2011. Assessment of left atrial volume: a focus on echocardiographic methods and clinical implications. Clin. Res. Cardiol. 100(2):97-105. http://dx.doi.org/10.1007/ s00392-010-0222-y. PMid:20821219.

Lang R.M., Bierig M., Devereux R.B., Flachskampf F.A., Foster E., Pellikka P.A., Picard M.H., Roman M.J., Seward J., Shanewise J.S., Solomon S.D., Spencer K.T., St John Sutton M. \& Stewart W.J. 2005. Recommendations for chamber quantification: a report from the American Society of Echocardiography's Guidelines and Standards Committee and the Chamber Quantification Writing Group, Developed in Conjunction with the European Association of Echocardiography, a Branch of the European Society of Cardiology. J. Am. Soc. Echocardiogr. 18(12):1440-1463. <http://dx.doi.org/10.1016/j. echo.2005.10.005> <PMid:16376782>

Leung D.Y., Boyd A., Ng A.A., Chi C. \& Thomas L. 2008. Echocardiographic evaluation of left atrial size and function: Current understanding, pathophysiologic correlates, and prognostic implications. Am. Heart J. 156(6):1056-1064. <http://dx.doi.org/10.1016/j.ahj.2008.07.021> <PMid:19032999>

Leung D.Y., Chi C., Allman C., Boyd A., Ng A.C., Kadappu K.K., Leung M. \& Thomas L. 2010. Prognostic implications of left atrial volume index in patients in sinus rhythm. Am. J. Cardiol. 105(11):1635-1639. <http:// dx.doi.org/10.1016/j.amjcard.2010.01.027> <PMid:20494675>

Lupu S., Mitre A. \& Dobreanu D. 2014. Left atrium function assessment by echocardiography - physiological and clinical implications. Med. Ultrasound 16(2):152-159. <PMid:24791847>

Manning W.J., Katz S.E., Douglas P.S. \& Silverman D.I. 1993. Atrial ejection force: a noninvasive assessment of left atrial systolic function. J. Am. Coll. Cardiol. 22(1):221-225. <http://dx.doi.org/10.1016/0735-1097(93)90838-R> $<$ PMid:8509545>

Moïse N.S. \& Fox P.R. 1999. Echocardiography and Doppler imaging, p.130171. In: Fox P.R., Sisson D. \& Moïse N.S. (Eds), Textbook of Canine and Feline Cardiology: principles and clinical practice. W.B. Saunders, Philadelphia.

Pritchett A.M., Jacobsen S.J., Mahoney D.W., Rodeheffer R.J., Bailey K.R. \& Redfield M.M. 2003. Left atrial volume as an index of left atrial size: a population-based study. J. Am. Coll. Cardiol. 41(6):1036-1043. <http:// dx.doi.org/10.1016/S0735-1097(02)02981-9><PMid:12651054>

Schober K.E., Hart T.M., Stern J.A., Li X., Samii V.F., Zekas L.J., Scansen B.A. \& Bonagura J.D. 2010. Detection of congestive heart failure in dogs by Doppler echocardiography. J. Vet. Intern. Med. 24(6):1358-1368. <http://dx.doi. org/10.1111/j.1939-1676.2010.0592.x><PMid:20840304>

Thomas W.P., Gaber C.E., Jacobs G.J., Kaplan P.M., Lombard C.W., Vet M., Moise N.S. \& Moses B.L. 1993. Recommendations for standards in transthoracic two-dimensional echocardiography in the dog and cat. J. Vet. Intern. Med. 7(4):247-252. <http://dx.doi.org/10.1111/j.1939-1676.1993.tb01015. $\mathrm{x}><$ PMid:8246215> 
Tidholm A., Ljungvall I., Höglund K., Westling A.B. \& Häggström J. 2009. Tissue Doppler and strain imaging in dogs with myxomatous mitral valve disease in different stages of congestive heart failure. J. Vet. Intern. Med. 23(6):1197-1207. <http://dx.doi.org/10.1111/j.1939-1676.2009.0403. $\mathrm{x}><$ PMid:19909428>

Tidholm A., Höglund J., Häggström J., Bodegard-Westling A. \& Ljungvall I. 2013. Left atrial ejection fraction assessed by real-time 3-dimensional echocardiography in normal dogs and dogs with myxomatous mitral valve disease. J. Vet. Intern. Med. 27(4):884-889. <http://dx.doi.org/10.1111/ jvim.12113><PMid:23731204>

To A.C.Y., Flamm S.D., Marwick T.H. \& Klein A.L. 2011. Clinical utility of multimodality LA imaging: assessment of size, function, and structure. J. Am. Coll. Cardiol. Imag. 4(7):788-798. <http://dx.doi.org/10.1016/j. jcmg.2011.02.018><PMid:21757171>
Triposkiadis F., Harbas C., Sitafidis G., Skoularigis J., Demopoulos V. \& Kelepeshis G. 2007. Echocardiographic assessment of left atrial ejection force and kinetic energy in chronic heart failure. Int. J. Cardiovasc. Imaging. 24(1):1522. <http://dx.doi.org/10.1007/s10554-007-9219-7><PMid:17394097>

Tsang T.S.M., Abhayaratna W.P., Barnes M.E., Miyasaka Y., Gersh B.J., Bailey K.R., Cha S.S. \& Seward J.B. 2006. Prediction of cardiovascular outcomes with left atrial size: Is volume superior to area or diameter? J. Am. Coll. Cardiol. 47(5):1018-1023. <http://dx.doi.org/10.1016/j.jacc.2005.08.077> <PMid:16516087>

Yoon H.J., Jeong M.H., Jeong Y., Kim K.H., Song J.E., Cho J.Y., Jang S.Y., Jeong H.C., Lee K.H., Park K.H., Sim D.S., Yoon N.S., Hong Y.J., Park H.W., Kim J.H., Ahn Y., Cho J.G., Park J.C. \& Kang J.C. 2013. Progressive dilation of the left atrium and ventricle after acute myocardial infarction is associated with high mortality. Korean Circ. J. 43(11):731-738.<http://dx.doi.org/10.4070/ kcj.2013.43.11.731><PMid:24363748> 